The 49th Annual Conference of the International Association of School Librarianship

The 24th International Forum on Research on School Librarianship

July $12-16,2021$

Cary Jim; Sarah Evans; Alison Grant

University of North Texas; University of North Texas; Purdue University

CaryJim@my.unt.edu; Sarah.Evans@unt.edu; grant73@purdue.edu

\title{
Multidimensional Approaches to Illustrate the Digital Divide among K-12 Students
}

\begin{abstract}
In this paper, we share the initial findings from a multi-disciplinary project by Team D2IE (Digital Divide and Inclusion in Education), the recent first-place winner of the Global XPRIZE Education Open Data Challenge, where they investigated how digital infrastructure and internet connectivity varies among K-12 students at the county level across the United States. Two quantitative measures (Student Digital Opportunity and Benefit-Cost Ratio) and three interactive maps were developed from socio-technical and economic perspectives to support decision-making. The three interactive maps allow stakeholders to evaluate digital access, usage, cost, and economic benefits at the county level across the country.
\end{abstract}

Keywords: digital divide, digital access, digital infrastructure, K-12 students, internet connectivity

\section{Introduction}

The digital divide has been widely discussed for three decades in the United States (Attewell, 2001; Cohron, 2015; Compaine, 2001; Gilbert, 2010; Kuttan \& Peters, 2003; Mossberger et al., 2003; Norris, 2001; Yu, 2006; van Dijk \& Hacker, 2003; van Dijk, 2006). Outside of the United States, scholars examine the digital divide within their countries and how it varies internationally. For example, the global digital divide between the developed and developing countries (James, 2003; Murelli, 2002), ICT utilization and expenditure in Japan (Nishida et al., 2014) or user differences among countries in Europe (Brandtzæg et al., 2011).

While there is not a lack of research on the digital divide among the general population, there is a limited amount of research focusing on school-aged children (K-12 education) in terms of their opportunity to access and use high speed internet (i.e., broadband) for learning and educational needs. For researchers and practitioners in the field of education or library sciences, it is known that collecting data at the individual level comes with many challenges, especially if we are to collect information from minors within K-12 education. The limitation of not being able to systematically collect micro-level data can limit our understanding of how different factors around the students' educational life influence their access and use of the internet and other digital technologies. More recent research shifts the focus to mobile network and hand-held technology due to the prevalence of smartphones and tablets. However, Quaglione et al. (2020) 
indicated that the current mobile technology (e.g., 3G or LTE) cannot be considered an equivalent alternative to fixed broadband. Many of us who own and use a mobile phone can attest from our experience, where mobile phone signals varied due to location (distance from a cellular tower) and surroundings.

Schools and libraries offer critical access and support for a student's educational experience, learning, and information activities. When schools and libraries across the world were forced to shut down due to the pandemic, the digital divide as an equity issue came to the forefront again. To address this issue effectively, we need a new approach to gather evidence of the problem. Our work focuses on using existing open data to support the investigation of the digital divide among school-aged children within the United States. This unique approach is different to the traditional way of using survey data to estimate access and use of high-speed internet and related technologies. We integrated various datasets on the same geographic level - county - within the U.S. to support our investigation of the digital divide among places where children are enrolled in K-12 public schools.

\section{Statement of Research Problem}

The lack of research on terrestrial broadband (including cable, copper, DSL, and fiber optics) access and use for education within the U.S. hinders our understanding of the digital divide among school-aged children. As part of an education open data challenge (Open Data Institute, 2020), we integrated various public data with the released broadband datasets to evaluate the state of digital divide among K-12 students and how resources can be allocated for the various regions within our country.

The research objectives of this project include: 1) evaluate the relationship between broadband availability, usage, and costs at the county level across the United States, 2) assess how broadband availability, usage, speed, and cost vary at the county level, 3) create a comparable measure to illustrate how access and use of broadband and digital technology vary for K-12 students, and 4) estimate societal benefit-cost ratios to inform resource allocation and investment strategies for public and private sectors.

\section{Literature Review}

Although, the library and information science (LIS) field does not lack research on the topic of the digital divide (Ball, 2009; Cohron, 2015; Mandel et al, 2010; Reynolds \& Chiu, 2016; Rice \& Katz, 2002; West 2011), the evolving nature of the digital divide due to technology advancement makes it a continuing challenge to address and stay relevant in research over time.

Early internet users may recall using dial-up connections with a noisy modem and a phone line to access the internet through a DSL connection from twenty years ago. Many of those born after 1995, often labeled as "digital natives", probably cannot imagine a world without broadband and feel incompetent without a smart phone. Although the young are born in the era of digital technology, is it fair to assume they all have equal access and skill to fully utilize the internet and 
computer technology? While digital penetration has increased in the United States to address access issues in certain areas, disparities remain persistent between urban and rural areas, especially internet use variations by race, income groups, and levels of education (Levitt, 2016). Previous scholars have described the digital divide phenomenon for the general population from various viewpoints. Norris (2001) emphasized the discussion of the digital divide at an international level where there is a global divide of internet access, a social divide of information rich or poor, and a democratic divide. Attewell (2001) looked at computer ownership at home and suggested disadvantaged children may tend to use computers for games at home while affluent children use it for educational enrichment, thus describing the digital divide as a social problem. Beside home access and usage, the students' experience at school also plays a role. Thomas et al. (2019) acknowledged that while there are existing challenges of device access, internet connectivity, and bandwidth issues among schools; the unequal use of technology in classrooms (e.g., practice among teachers) continues to be a barrier to close the digital equity gap.

Staff at the public library also face different challenges in navigating the digital divide issue. Ball (2009) argued the need for public librarians to understand funding and technical aspects of broadband, then form coalitions to leverage resources to provide internet and information access for their communities. While the conversation of the digital divide may have shifted to skills and/or literacy, maintaining access continues to be the primary gap for many in the U.S. (Cohron, 2015).

Recent technological innovations have been implemented to narrow the digital divide in creative ways. For example, recent efforts by private organizations such as the Microsoft Airband Initiative (McKinley, 2020) launched in 2017 aimed to bring broadband connectivity to 3 million people living in unserved rural areas of the U.S. This approach repurposed a technology called the TV white space without interference to other signals (Wifi Forward, 2020) while providing broadband access to communities in the rural area.

Another nationwide effort is underway to solve the "homework gap" problem by providing emergency relief to schools and libraries to support remote learning during the pandemic (Federal Communications Commission, 2021). Similar to what previous scholars have discussed, private and public initiatives can address the need for digital infrastructure in different parts of the country. However, the "availability of internet infrastructure does not directly translate into adoption" (Reisdorf et al., 2019, p. 3814).

\section{Access vs. Usage}

To have a better understanding of how broadband availability and usage vary at the state level, we utilized aggregated dataset from two sources and created a comparison chart for visual examination (Figure 1). The aggregated data from the IMLS Indicators Workbook: Economic 
Status and Broadband Availability and Adoption (2020) provides state-level broadband availability information in the U.S. The Microsoft released broadband usage data (Misra et al., 2020) provides the estimated usage of the internet at broadband speed across the country. By examining the comparison chart (Figure 1), we see that while broadband appears mostly available in the 50 states, internet usage at broadband speed (at least $25 \mathrm{Mbps}$ for download) is much less in many places. This information reflects the discrepancy between broadband access and use at the state level within our country.

\section{Figure 1}

\section{Broadband Availability versus Broadband Usage per Population in the 50 States}

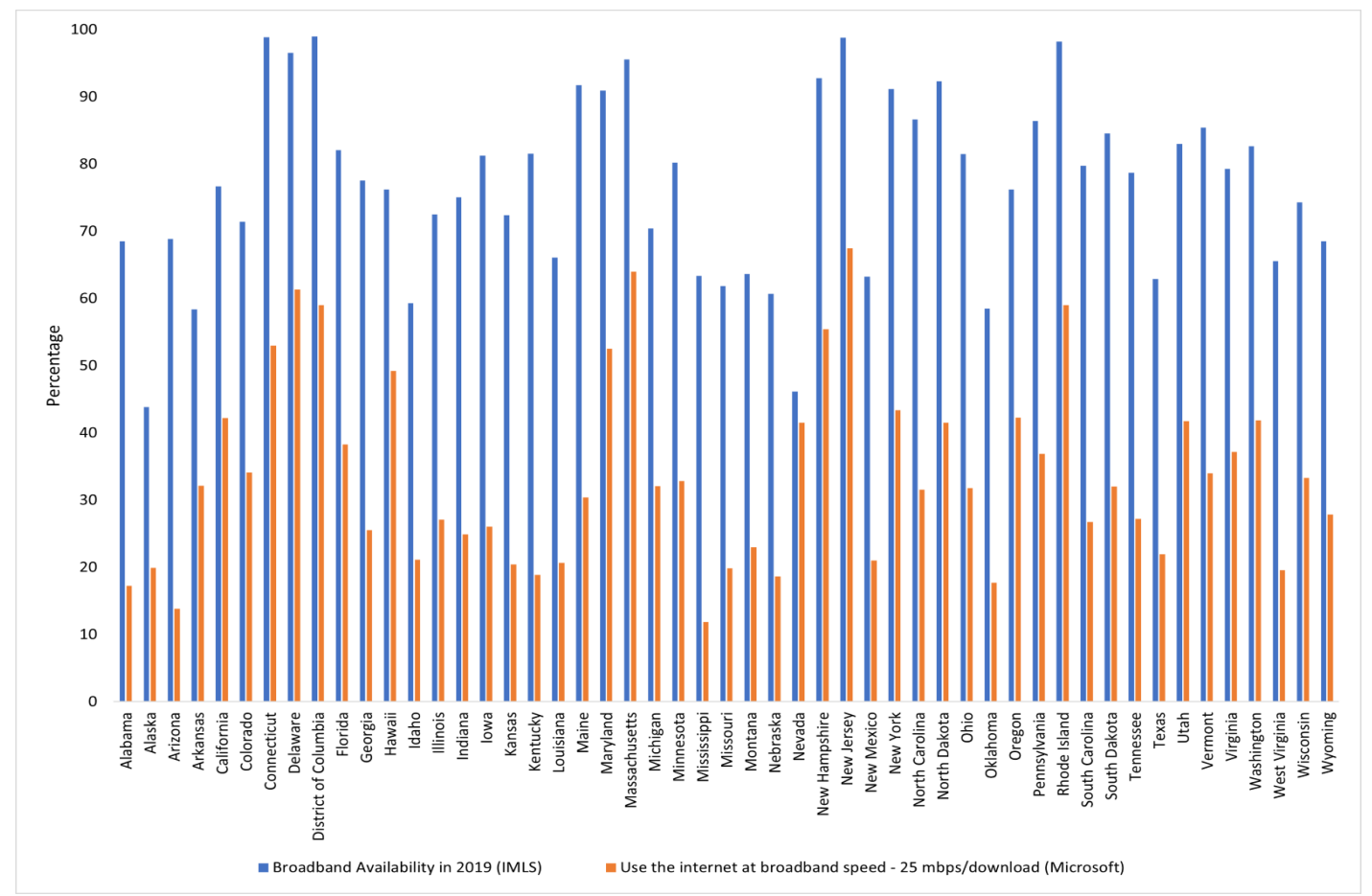

Thus, we used a data-driven approach to study and analyze the digital divide from a multi-disciplinary approach to assess and quantify this phenomenon. This approach is new to the library and information science (LIS) field due to its use of multiple data sources to investigate the digital divide. The integration of other disciplines, i.e., education, economics, and data science, with LIS provided a holistic view of the digital divide that can further inform study and research at the local levels.

\section{Methodology}

\section{Data Sources}

It is essential to identify suitable measures at a geographic layer that allows an initial evaluation of the digital divide among K-12 public school students. After examining the collected public data from governmental sources and the released datasets (BroadbandNow, 2021; Misra et al, 2020), we selected the county level as the unit of analysis. The county level is the most suitable 
geographic layer for the current analysis which allows meaningful comparison and visualization of the digital divide on a national map.

We aggregated public school's administrative data (National Center for Education Statistics, 2018; 2019), rurality information (U.S. Census Bureau, 2010), and computer \& internet access for households with children under 18 (U. S. Census Bureau , 2019a; 2019b). There is a time consideration while collecting these data, in which the released broadband datasets were collected between 2017 - 2019. Therefore, we extracted the governmental datasets within a similar time frame to reflect the observations around those years.

\section{Quantitative Composite Measure and Economic Indicator}

To formalize the conception of student digital opportunity and operationalize this construct for quantitative analysis, there are several aspects to consider. From our perspective, we consider the term "digital inequality" a better representation to explain the differences among students' access, use, or application of digital technology and resources for their learning and information needs. Hilbert (2014) emphasized that "inequality is a relative, not an absolute measure. Even if everyone advances, some can advance more than others, potentially increasing relative inequality" (p. 823). With this frame of reference, we created a measure to represent the digital divide as a continuum among school-aged children within the United States.

Currently, there are several conceptualizations of digital divide or digital inequality. van Dijk and Hacker (2003) distinguished four types of access barriers: mental, material, skill, and usage, where a person's access issues would gradually shift from the first two barriers to the latter two. Ragnedda (2019) described a three-level model of digital divide where physical access is at the first level, differences in digital skills and uses of the internet are at the second level. Due to the difference in access and use from the first two levels, the associated social and tangible benefits at the third level distinguish the inequalities among people (p. 35). Other researchers examined it from a long-term perspective where ongoing cost (van Deursen \& van Dijk, 2019) and technology maintenance beyond the initial access continues to be a barrier for low-income groups (Gonzales, 2016).

Based on the previous literature and the lack of a holistic measure that looks beyond internet access, a composite variable was developed to represent the multidimensional nature of the digital divide among K-12 students. The Students' Digital Opportunity (SDO) is a composite measure to represent the four components of digital connectivity: access, usage, speed, and ownership of digital devices (Figure 2). The SDO can be treated as the "prerequisite" in terms of connectivity and equipment ownership before any students can tap into existing learning resources online for their educational needs. The SDO composite measure is estimated for each county in the United States. 
While internet access, usage, and skills are discussed as the first and second level of the digital divide. There is a third level that is often not discussed which examines social and economic benefits quantitatively for policymakers to make decisions on broadband or technology investment. A benefit-cost analysis was conducted to estimate a benefit-cost ratio at the county level for decision-making in resource allocation. The costs and benefits are derived from a social perspective, meaning the costs and benefits would not just accrue to governments or internet providers, but to many groups in society as a whole. This allows us to assess whether increased access and connection would produce large enough educational benefits by geographic area, subject to the region's estimated cost constraints.

\section{Figure 2}

\section{Students' Digital Opportunity (SDO) Conceptual Model with Open Data}

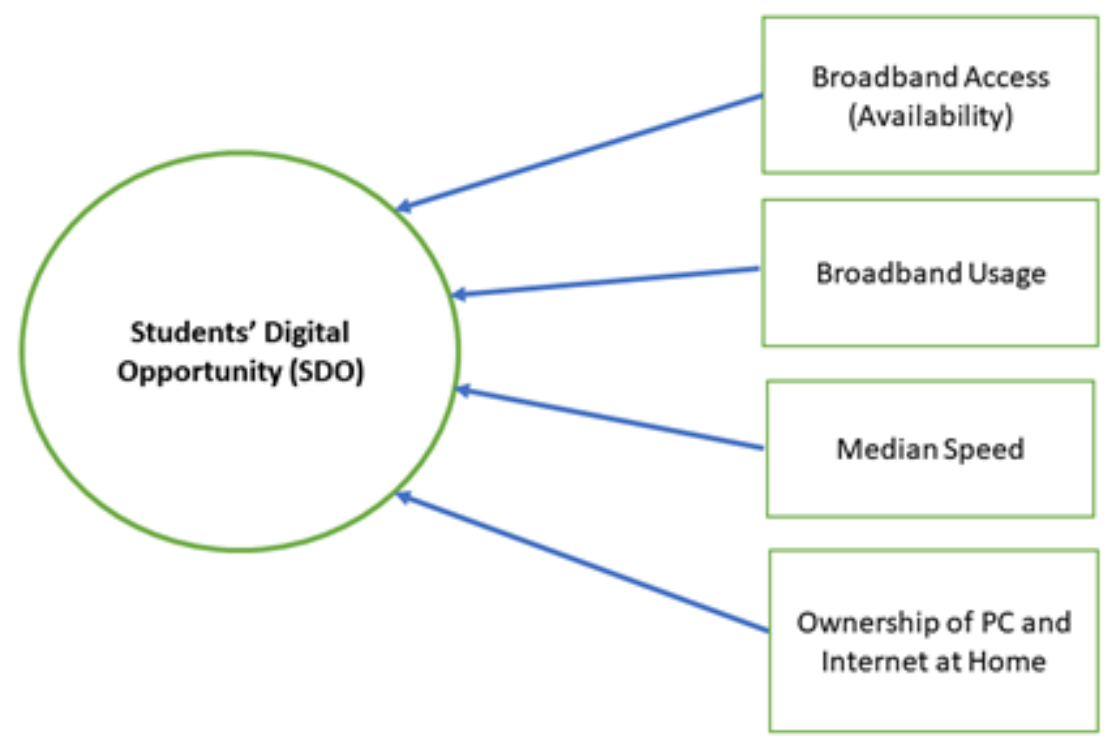

\section{Methodology Challenges}

This research approach of using open data is not without challenges. From a measurement point of view, variables will require rescaling and transformation in order to allow "apples to apples" comparison. Another aspect of our methodology is to adapt psychometrics principles where a latent construct is of interest. This approach is commonly used in educational measurement when there is a latent construct that consists of multiple dimensions (DiStefano et al., 2009; OECD, 2008). There is also a lack of open data at the micro-level where we can examine digital literacy as part of the underlying factors. Thus, we acknowledge the importance of digital skills and literacy data while we focused on evaluating access and usage among the student population as a first step of our work. 


\section{Findings}

The final dataset includes terrestrial broadband information, school characteristics, socioeconomic measures, and geographical information. Exploratory data analysis through descriptive statistics provided insights into the features and relationships of the selected variables in the dataset (Table $1 \& 2$ ). An interesting result is the correlational relationship among the selected variables. Broadband access, usage, and speed are negatively correlated with rurality, meaning the more rural an area is, the less in access, usage, and speed for families in those regions (see Table 2).

Table 1

Descriptive Statistics of Selected Variables

\begin{tabular}{|c|c|c|c|}
\hline Variable & Mean & Median & $\begin{array}{l}\text { Standard } \\
\text { Deviation }\end{array}$ \\
\hline Percentage of Broadband Availability (FCC) & 0.76 & 0.84 & 0.24 \\
\hline Percentage of Broadband Usage (Microsoft) & 0.28 & 0.24 & 0.19 \\
\hline $\begin{array}{l}\text { Number of Providers of Broadband at } 25 / 3 \mathrm{Mbps} \text { (per } \\
\text { County) }\end{array}$ & 2.39 & 2.12 & 1.42 \\
\hline Lowest Monthly Internet Plan Price (Reported by ISPs) & 45.89 & 45.12 & 21.31 \\
\hline Median Speed (Mbps) & 26.93 & 15.76 & 29.31 \\
\hline Percentage of Rurality (U.S. Census Bureau) & 58.64 & 59.49 & 31.44 \\
\hline $\begin{array}{l}\text { Percentage of Home with PC and Internet (with } \\
\text { school-aged children) }\end{array}$ & 0.89 & 0.92 & 0.07 \\
\hline
\end{tabular}

Note. The final number of counties in the dataset is 3138 where there is at least one school in operation. 
Table 2

Correlations for Selected Variables $(\mathrm{N}=3138)$

\begin{tabular}{lcccc}
\hline \multicolumn{1}{c}{ Variable } & Access & Usage & Speed & Rurality $\begin{array}{c}\text { PC and } \\
\text { Internet }\end{array}$ \\
\hline Percentage of Broadband Availability (FCC) & 1 & & & \\
Percentage of Broadband Usage (Microsoft) & .67 & 1 & & \\
Median Speed (Mbps) & .47 & .56 & 1 & \\
Percentage of Rurality (U.S. Census Bureau) & -.54 & -.68 & -.46 & 1 \\
& & & & \\
Percentage of Home with PC and Internet & .27 & .39 & .18 & -.23 \\
(with school-aged children) & & & & \\
\hline
\end{tabular}

By examining the visualizations, we found that broadband availability and usage at the county level $(\mathrm{N}=3138)$ presented a positive relationship; however, this relationship is not linear (Figure $3)$. Counties that reported having a high percentage $(>85 \%)$ of broadband availability displayed a wider range of usage (between $0 \%-100 \%$ ). Counties on the lower end of broadband availability $(<40 \%)$ are limited in terrestrial broadband access and their reported usage of high-speed internet are mostly on the lower range $(<40 \%)$ for their population.

We also explored the distribution of broadband availability and usage with two histograms to evaluate the overall range of access and use among the 3138 counties where at least one K-12 schools are in operation (Figure $4 \& 5$ ). In Figure 4, the histogram displayed the distribution of broadband availability in percentages where county is organized by frequency count per bin. This information is reported by the Internet Service Providers to the Federal Communications Commission (FCC) as to what percentage of the county population have access to terrestrial broadband internet (including cable, copper, DSL, and fiber optics). We can see that roughly $47 \%$ counties within the U.S. (about 1485 counties out of 3138 counties) were reported to have access to terrestrial broadband for at least $85 \%$ of their population.

The distribution of broadband usage in percentages where county is organized by frequency count per bin is displayed in Figure 5. We see that most counties in the U.S. fall on the lower to middle range of broadband usage. This released data from Microsoft (Misra et al., 2020) represents an estimated usage information, where they were able to assess if users are using the 
internet at broadband speed, which is $25 \mathrm{Mbps}$ per download on the computer, across the country.

Figure 3

Relationship Between Broadband Availability and Usage per County in U.S.

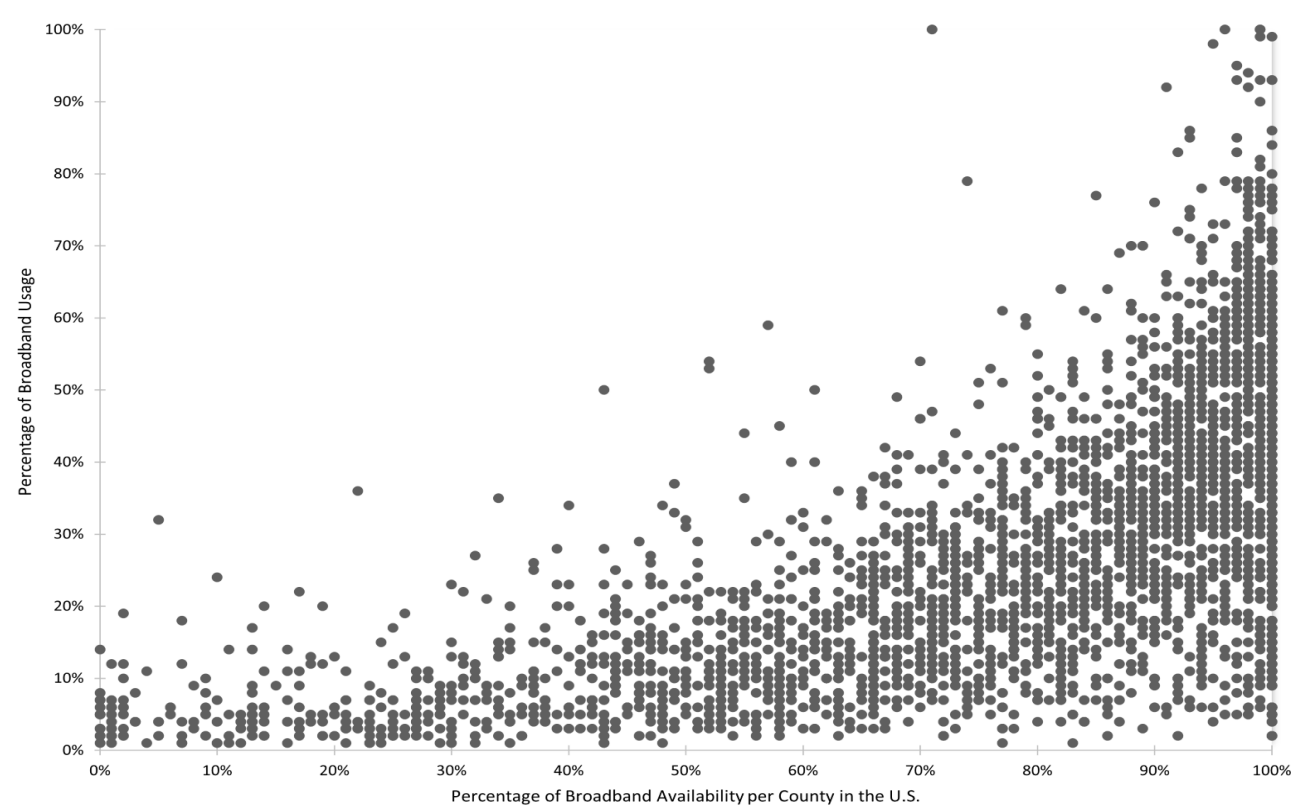

Figure 4

Distribution Broadband Availability at the County Level

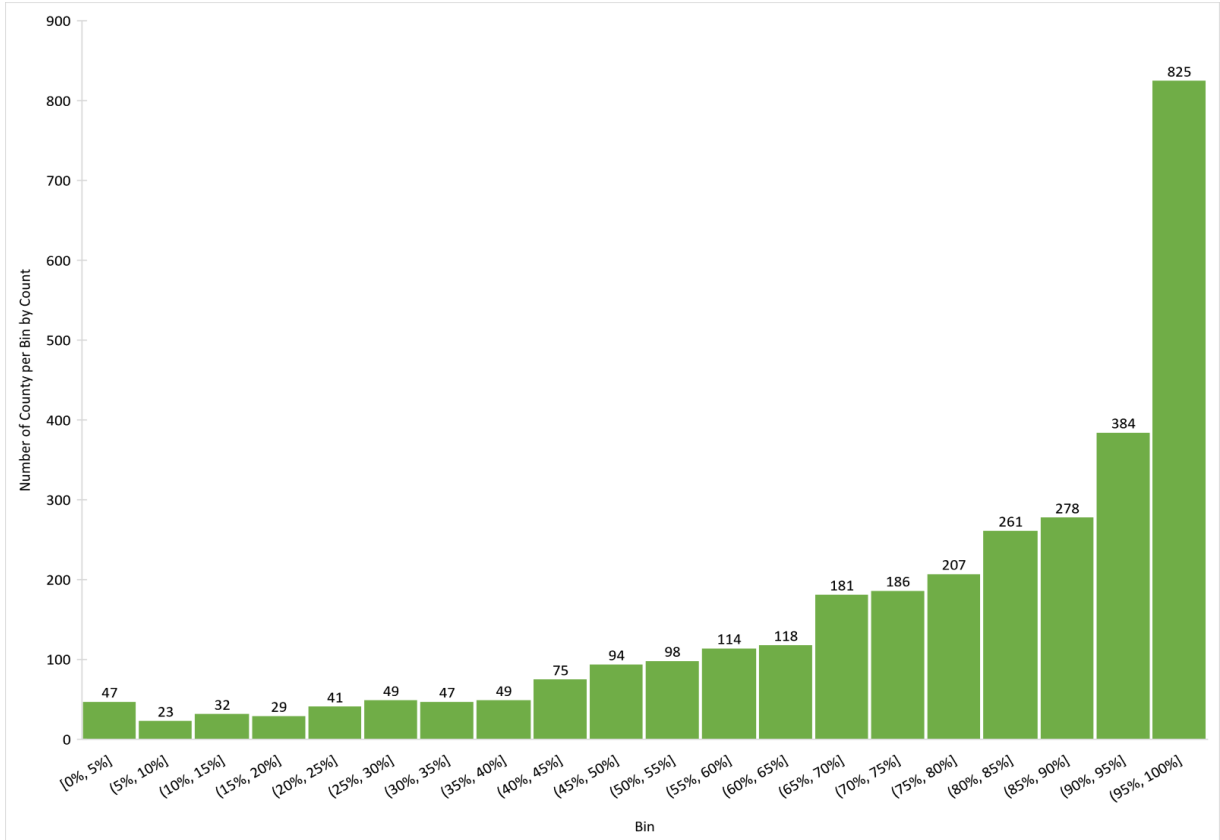




\section{Figure 5}

\section{Distribution of Broadband Usage at the County Level}

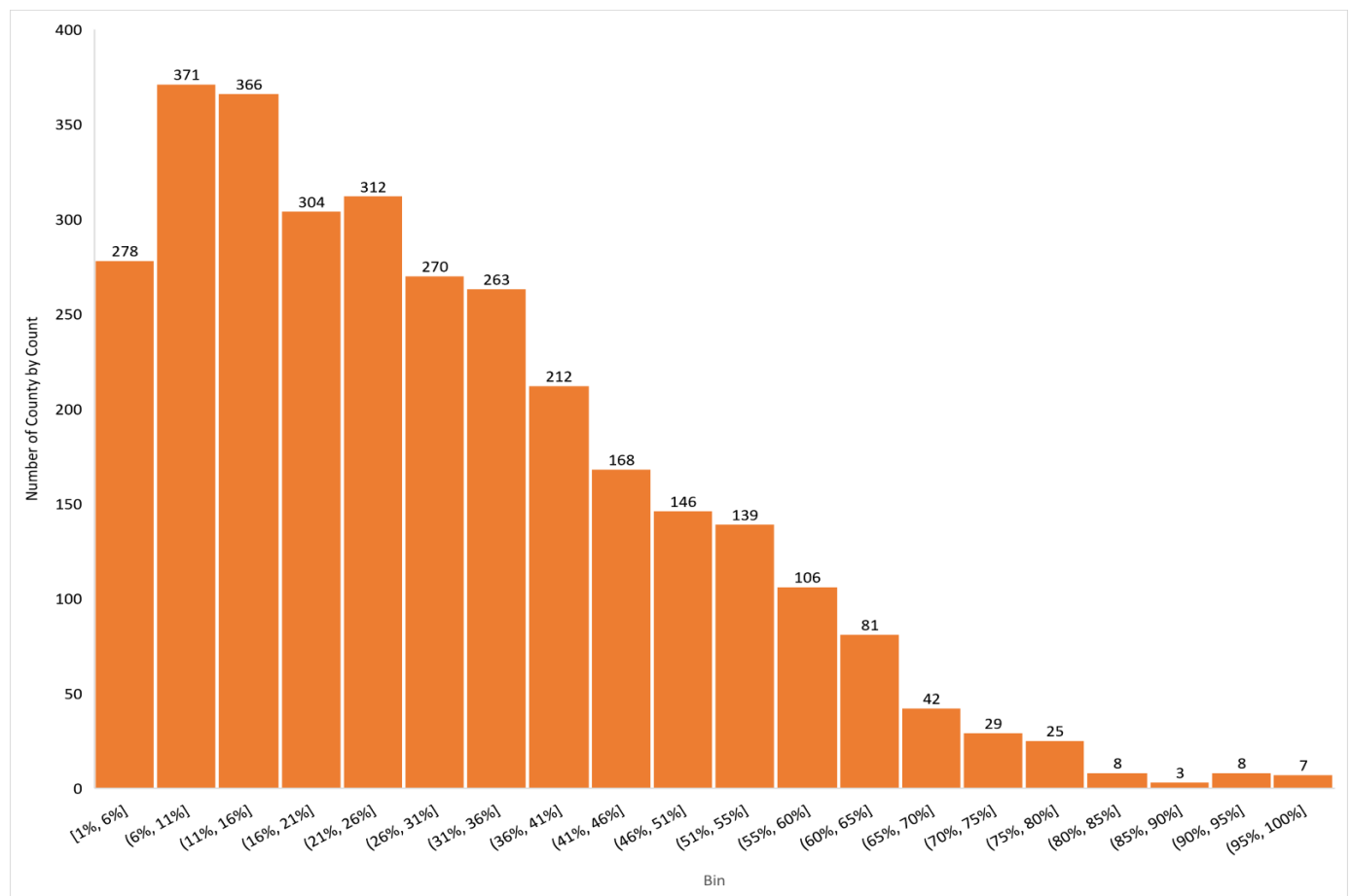

To further explore the differences regarding broadband access, use, and pricing information, we developed three visualizations in map formats to illustrate the status of the digital divide across different counties and aid decision-making in resource allocation (Figure 6).

\section{Figure 6}

Broadband Availability, Usage and Pricing Information by Country, 2020

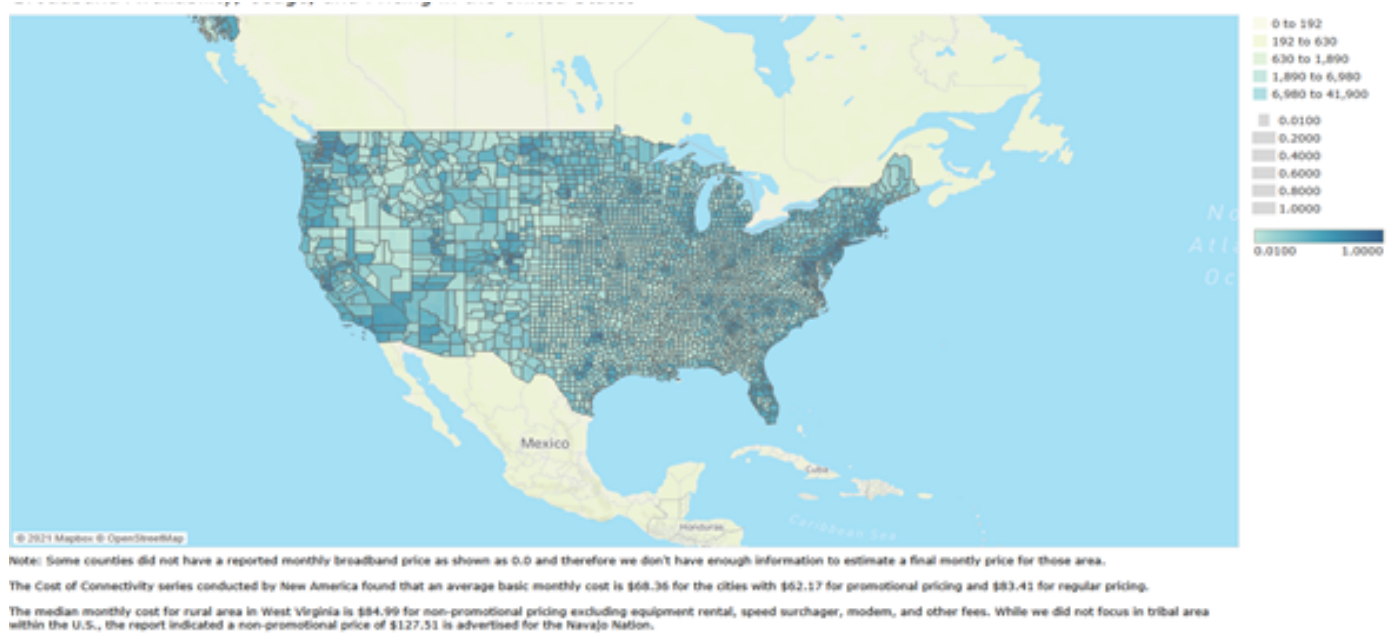

Note. The interactive version of this map along with the other two are available online in Tableau Public at https://public.tableau.com/app/profile/cary.k.jim/viz/EducationOpenDataChallenge-D2IETeam/SDO 


\section{Students Digital Opportunity (SDO)}

The SDO measure is a composite measure to compare digital opportunity in terms of broadband access, usage, speed, and computer ownership with internet subscription among households with school-aged children within each county. This composite measure has a mean of zero and a standard deviation of 1 for relative comparison. The SDO gives the relative position of students who reside in each county in terms of their digital opportunity as defined in this construct.

During the data exploration, we discovered that three counties in the U.S. do not have public schools in operation for the 2017-2018 school years. Therefore, we only estimated the SDO measure for 3138 counties in the U.S. By examining the distribution of the SDO among all the counties in this dataset, we found that there are several counties at the higher end as outliers. The median value (- 0.18) falls below the mean, with the SDO score ranges from -1.5 to 3.89 .

We used a box and whisker plot to illustrate the distribution of the SDO score (Figure 7). The relative short box and its position on the scale suggests that most students have a low level of digital opportunity among the various counties. While examining the lower whisker, we observed smaller differences for students who are positionally below average in their digital opportunity. The upper whisker is longer in length and indicates a greater variation of digital opportunity among those positionally above average. This suggests that students in the upper range experience a larger variation in their digital opportunity.

\section{Figure 7}

Students' Digital Opportunity (SDO) Score Distribution

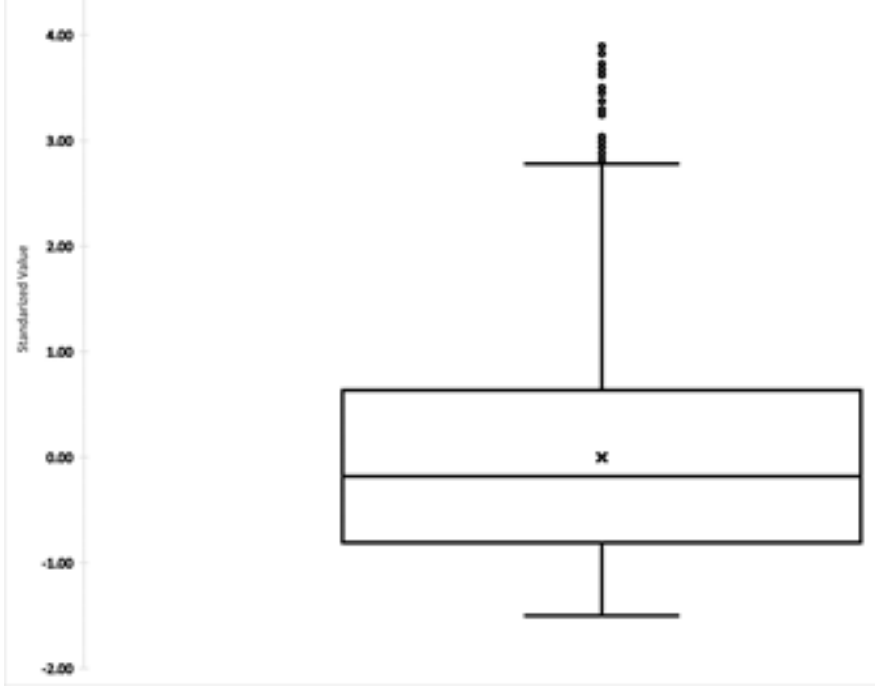

Note. X indicates the mean of the SDO measure, and the median value is below the mean of zero. 


\section{Figure 8}

\section{Benefit Cost Ratio Map}

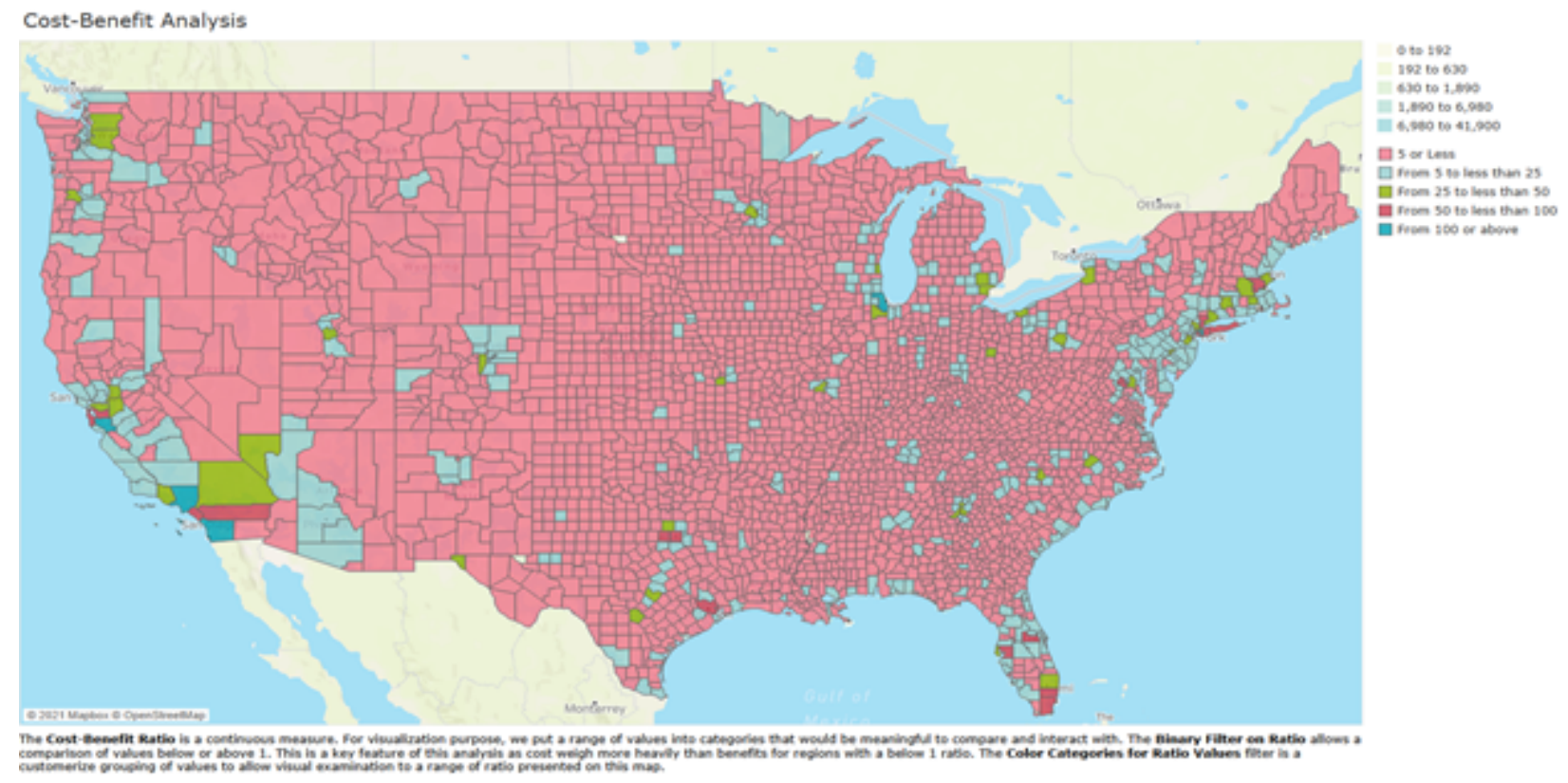

Benefit-Cost Ratio (BC ratio)

A cost-benefit analysis was conducted to estimate the benefit-cost ratio at the county level. The cost for broadband investment includes capital and operating cost for broadband access, hardware, and speed quality. The educational benefit includes improved teacher salaries and increased student performance by earnings and educational attainment. Since only K-12 education-derived benefits were measured, a scaling factor was used to allow estimates to be comparable (Grant \& Tyner, 2018).

Similar to the construction of the SDO variable, the benefit-cost ratio was estimated for the 3138 counties where operating public schools were present during the 2017-2018 school year. The benefit-cost ratio from this analysis ranges from 0.01 to 311.04 meaning for every US dollar invested into broadband to improve access and quality, a return in US dollars could range from $\$ 0.01$ to $\$ 311.04$ for the different counties within the U.S. For a full comparison of the benefit-cost ratio at the county level, a map is created to visualize this information (Figure 8).

\section{Discussion}

\section{Broadband Availability}

Based on our findings, the reported broadband availability data per county aggregated by BroadbandNow sourced from the FCC is not a reliable way to determine if residents are using a broadband connection to access the internet. One of the limitations of the FCC data is due to the self-reporting nature of broadband availability by internet service providers (ISPs) as to whether 
they provide broadband services at the local level. In our descriptive analysis, even though access and usage presented a positive relationship, the actual usage varies greatly among counties with high percentage of broadband availability. This indicated that having broadband available does not equate to adoption and use in these regions. Counties on the lower end of broadband availability $(<30 \%)$ are limited in terrestrial broadband access and thus usage can be expected to be low as well.

The different types of broadband services related to pricing and speed are often not explicitly discussed in the literature. For example, based on where you live, your internet options could be limited and have to choose between distinct types of technology, e.g., fiber optics vs. cable in urban or suburban areas. You may have only one type of internet service available, such as satellite broadband, if you live in a rural area. However, fiber optics, cable, or satellite broadband are not the same kinds of technology. Cable internet slows significantly when more people share this form of connection in your area, where fiber-optics connection quality is not affected by this factor. Satellite broadband has a high upfront cost of equipment and installation, and its connection quality could be affected by the weather. We found that broadband subscription cost is not a good predictor of internet access and usage. This is due to the different pricing strategies used in areas that have competition versus little or no competition. In sum, the differences in access and use of broadband, ownership, and utilization of technology equipment, such as personal computer, and speed variation (e.g., disruption of broadband internet regardless of the price paid for an expected speed) are the primary factors driving the digital divide.

\section{SDO and Benefit-Cost Ratio}

A limitation of the SDO and the benefit cost ratio is their estimated values for small areas. For areas with small populations, estimates on broadband access, use, and computer ownership are not as reliable due to the sample size or missing values in the datasets. This is an ongoing challenge of evaluating how the digital divide is experienced by students living in less populated areas.

One interesting discovery based on our result is that not all rural areas experienced the same kind of challenge in terms of broadband access or usage. For example, many counties in North Dakota may have a small enrollment of K-12 students $(<10,000)$, however, the estimated opportunity for digital connection and technology for students in those counties are above average (mean) comparatively. Also, the box plot (Figure 7) displays the within group variation among students below average in the SDO in comparison to the above average in the SDO score, even though students positionally above average, they have a much-varied opportunities among the different counties. 
Therefore, investigating other characteristics at a local level, such as local/state policy on broadband regulations or presence of higher education institutions, may help further understand the population characteristics in relation to their digital connectivity.

\section{Policy Recommendations}

We suggest differentiated solutions to address short-term and long-term needs for digital connectivity and technology to address the digital divide among K-12 students. Our philosophy is to take an inclusive approach where socio-technical conditions and economic development are both considered.

Based on the estimated $\mathrm{BC}$ ratio, many counties in the U.S. have a below one ratio which indicates that initial investments (cost) in digital infrastructure may be too high for communities in those areas to increase access to broadband with quality connection. This suggests the need for public investments (e.g., state, and federal) to first address the access issue among the counties with a low benefit-cost ratio. High estimated benefit-cost ratios are mainly observed in areas with high population densities. These areas would benefit most from increased access and internet quality. Since potential investments would have a higher payoff in high benefit-cost regions, perhaps these regions could be supported with private or community investments to expand broadband to various social groups and improve their internet quality. In sum, investments between public and private partnerships can address immediate and intermediate needs at the school level. A broader, longer-term need is to provide support at the community level where skills and other socio-psychological factors (e.g., culture, attitudes, and beliefs) play a role in how people are participating and utilizing digital infrastructure.

Based on the Students' Digital Opportunity (SDO) measure, we recommend ongoing improvement of broadband access in high-need areas with targeted training and resources to increase their adoption and use of the internet. For urban and suburban areas, low-income families can benefit from low-cost internet subscription and skills training to improve their adoption of broadband and online engagement. As Warschauer (2003) suggested, a multifaceted approach should be applied not only to situations where internet penetration is high, but also in places where it is low or just beginning. The need to promote skill, social support, and autonomy for places that are just beginning to expand their internet penetration will be most important (p. 199). Supporting teachers and families with their digital needs are especially important for the school-aged children. When teachers and parents are at an advantageous position in using and adopting digital technologies, they could be serving as role-models for their students to understand how the use of technology can enhance learning and improve economic outcomes.

\section{Implications and Conclusions}

Even though scholars have claimed that many people have moved beyond the first level of the digital divide, what is the evidence to support this claim? Cohron (2015) suggested that the core of digital divide is not simply providing access to the internet and computers, "it is about 
leveling the playing field in regard to information diffusion" (p. 84). This study attempts to do that by proving a standardized measure in a continuum to assess the digital divide. The suggested approach and methodology in evaluating the digital divide with open data is a replicable way for others in the LIS field. For international comparison, we need a better understanding of how high-speed internet or broadband availability, and usage is measured and evaluated at each country for a probable comparison.

As $\mathrm{Yu}$ (2006) pointed out, "the concept of digital divide is often used to advance political interests rather than to improve the understanding of the issues" (p. 243). Therefore, the library and information science community are in a position to advance the understanding of digital inequality as we are at the nexus of people, information, and technology.

To conclude, we recognize the lack of comparative measures, as well as a comprehensive assessment of digital connectivity beyond broadband access in the United States. The new Students' Digital Opportunity (SDO) measure provides an understanding of digital opportunity for K-12 public school students across counties and states. Our benefit-cost analysis provides a clear way of targeting investment according to varying priority at the county level. The determination of return on investment, by county, could be valuable for policy makers and community members in decision making. Local leadership could partner with federal, state, and other funders to determine and negotiate with broadband businesses for their digital needs. Our results bridge the strength of data science, education, and economic research. We plan to continue this work by collaborating with local organizations to further understand the nuances of the digital divide at the local level. For example, our current study could be enhanced by collecting additional information such as what types of technology related services school or public libraries have provided to their student population. While mobile technology has been discussed as a promising alternative, much work is needed to understand what type of mobile network is suitable, with what kinds of equipment, and how reliable it is for children's educational needs in the long run. We suggest school librarians continue their work in advocating for low-cost reliable internet and equipment access for school-aged children and consider the use of open data to enhance their discussion with policy makers.

\section{Acknowledgement}

We thank Brent T. Ladd (Director of Education, Center for Science of Information at Purdue University) for serving as our team advisor during the XPrize Education Open Data Challenge sponsored by Microsoft and Open Data Institute (UK). We thank the following D2IE team members: Mai Anh Tran Nguyen (Bryn Mawr College) for her support on data collection and literature review on digital skills; Nathan R. Kanter (Purdue University) for constructing the base map in Tableau; and Kena Nicol (Dallas College) for her advice on presenting spatial data in maps. 


\section{References}

Attewell, P. (2001). The first and second digital divides. Sociology of Education, 74(3), 252-259. https://doi.org/10.2307/2673277

Ball, M. A. (2009). Aggregating broadband demand: Surveying the benefits and challenges for public libraries. Government Information Quarterly, 26(4), 551-558. https://doi.org/10.1016/j.giq.2009.05.004

Brandtzæg, P. B., Heim, J., \& Karahasanović, A. (2011). Understanding the new digital divide A typology of Internet users in Europe. International Journal of Human Computer Studies, 69(3), 123-138. https://doi.org/10.1016/j.ijhcs.2010.11.004

BroadbandNow. (2021, January). Zipcode Competition \& Pricing Data. [Data set] https://github.com/BroadbandNow/Open-Data

Cohron, M. (2015). The continuing digital divide in the United States. Serials Librarian, 69(1), 77-86. https://doi.org/10.1080/0361526X.2015.1036195

Compaine, B. M. (2001). The digital divide: Facing a crisis or creating a myth? The MIT Press

DiStefano, C., Zhu, M., \& Mîndrilă, D. (2009). Understanding and using factor scores: Considerations for the applied researcher. Practical Assessment, Research and Evaluation, 14(20), 1-11.

Federal Communications Commission. (2021). Homework Gap and Connectivity Divide. https:/www.fcc.gov/about-fcc/fcc-initiatives/bridging-digital-divide-all-americans

Gilbert, M. (2010). Theorizing digital and urban inequalities. Information, Communication \& Society, 13(7), 1000-1018. https://doi.org/10.1080/1369118X.2010.499954

Gonzales, A. (2016). The contemporary US digital divide: from initial access to technology maintenance. Information Communication and Society, 19(2), 234-248. https://doi.org/10.1080/1369118X.2015.1050438

Grant, A., \& Tyner, W. E. (2018). Benefit-Cost analysis for implementation of rural broadband in the Tipmont cooperative in Indiana (Research \& Policy Insights, Publication 005). Purdue Center for Regional Development. https://pcrd.purdue.edu/wp-content/uploads/2018/12/005-RPINsights-Tipmont-Broadban d.pdf

Hilbert, M. (2014). Technological information inequality as an incessantly moving target: The redistribution of information and communication capacities between 1986 and 2010. Journal of the Association for Information Science and Technology, 65(4), 821-835. https://doi.org/10.1002/asi.23020

Institute of Museum and Library Services. (2020). Economic status and broadband availability and adoption [Data set and code book]. https://www.imls.gov/data/data-catalog/imls-indicators-workbook-economic-status-and-b roadband-availability-and-adoption

James, J. (2003). Bridging the Global Digital Divide. Edward Elgar Publishing Limited.

Kuttan, A., \& Peters, L. (2003). From digital divide to digital opportunity. Scarecrow Press, Inc. Levitt, R. (2016). Housing, Community Development, and the Digital Divide (Evidence Matters, 
Fall 2016 Issue). U.S. Department of Housing and Urban Development's Office of Policy Development and Research (PD\&R).

https://www.huduser.gov/portal/periodicals/em/fall16/index.html

Mandel, L. H., Bishop, B. W., McClure, C. R., Bertot, J. C., \& Jaeger, P. T. (2010). Broadband for public libraries: Importance, issues, and research needs. Government Information Quarterly, 27(3), 280-291. https://doi.org/10.1016/j.giq.2010.02.004

McKinley, S. (2020, March 5). Microsoft Airband: An annual update on connecting rural America. Microsoft On the Issues. https://blogs.microsoft.com/on-the-issues/2020/03/05/update-connecting-rural-america/

Misra, A., Kim, A., Kahan, J., Ferres, J. M. L., Pereira, M., White, K., \& Ewing, A. (2020). United States Broadband Usage Percentages Dataset [Readme]. https://github.com/microsoft/USBroadbandUsagePercentages/blob/fbbffa87d69500b686e 6d9998bc5bc475e837cba/README.md

Mossberger, K., Tolbert, C. J., \& Stansbury, M. (2003). Virtual Inequality. Georgetown University Press.

Murelli, E. (2002). Breaking the Digital Divide: Implications for Developing Countries. (R. W'O Okot-Uma, Ed.). Commonwealth Secretariat/SFI Publishing.

National Center for Education Statistics (NCES). (2019). Common Core of Data (CCD) SY 2017-2018 School District Finance Survey (F-33) [Data set]. https://nces.ed.gov/ccd/ccddata.asp

National Center for Education Statistics (NCES). (2018). Elementary/Secondary Information System. https://nces.ed.gov/ccd/elsi/

Nishida, T., Pick, J. B., \& Sarkar, A. (2014). Japan's prefectural digital divide: A multivariate and spatial analysis. Telecommunications Policy, 38(11), 992-1010. https://doi.org/10.1016/j.telpol.2014.05.004

Norris, P. (2001). Digital Divide: Civil Engagement, Information Poverty, and the Internet Worldwide. Cambridge University Press.

OECD. (2008). Handbook on constructing composite indicators: methodology and user guide. https://www.oecd.org/sdd/42495745.pdf

Open Data Institute. (2020, November 10). Education open data challenge: The impact of digital access on education during Covid-19.

https://theodi.org/article/education-open-data-challenge-the-impact-of-digital-access-on-e ducation-during-covid-19/

Quaglione, D., Matteucci, N., Furia, D., Marra, A., \& Pozzi, C. (2020). Are mobile and fixed broadband substitutes or complements? New empirical evidence from Italy and implications for the digital divide policies. Socio-Economic Planning Sciences, 71, 100823. https://doi.org/10.1016/j.seps.2020.100823

Ragnedda, M. (2019). Conceptualising the digital divide. In B. Mutsvairo \& M. Ragnedda $\backslash$ (Eds.), Mapping the Digital Divide in Africa: A Mediated Analysis (pp. 27-43). Amsterdam University Press. https://doi.org/10.5117/9789462986855 
Reisdorf, B. C., Yankelevich, A., Shapiro, M., \& Dutton, W. H. (2019). Wirelessly bridging the homework gap: Technical options and social challenges in getting broadband to disconnected students. Education and Information Technologies, 24(6), 3803-3821. https://doi.org/10.1007/s10639-019-09953-9

Reynolds, R., \& Chiu, M. M. (2016). Reducing digital divide effects through student engagement in coordinated game design, online resource use, and social computing activities in school. Journal of the Association for Information Science and Technology, 67(8), 1822-1835. https://doi.org/10.1002/asi.23504

Rice, R. E., \& Katz, J. E. (2002). Comparing internet and mobile phone digital divides. Proceedings of the American Society for Information Science and Technology, 39(1), 92-98. https://doi.org/10.1002/meet.1450390110

Thomas, S., Howard, N. R., \& Schaffer, R. (2019). Closing the Gap: Digital Equity Strategies for the K-12 Classroom. ISTE.

U. S. Census Bureau. (2010). County Rurality Level : 2010 (2010 Census, Summary File 1, Table P2). https://www2.census.gov/geo/docs/reference/ua/County_Rural_Lookup.xlsx

U. S. Census Bureau. (2019a). Median Income in the past 12 months in 2019 inflation-adjusted dollars (Table ID : S1903). https://data.census.gov/cedsci/table?q=S1903\&tid=ACSST5Y2019.S1903\&hidePreview $=$ false

U. S. Census Bureau. (2019b). Age by Presence of a Computer and Types of Internet Subscription in Household 20195 years estimates (Table 28005). Retrieved from https://data.census.gov/cedsci/table?q=ACSDT1Y2019.B28005\&tid=ACSDT5Y2019.B2 8005\&hidePreview $=$ true

Van Deursen, A. J. A. M. J., \& van Dijk, J. A. A. G. M. (2019). The first-level digital divide shifts from inequalities in physical access to inequalities in material access. New Media and Society, 21(2), 354-375. https://doi.org/10.1177/1461444818797082

Van Dijk, J. A. G. M. (2006). Digital divide research, achievements and shortcomings. Poetics, 34(4-5), 221-235. https://doi.org/10.1016/j.poetic.2006.05.004

Van Dijk, J., \& Hacker, K. (2003). The digital divide as a complex and dynamic phenomenon. Information Society, 19(4), 315-326. https://doi.org/10.1080/01972240309487

Mark Warschauer. (2003). Technology and Social Inclusion: Rethinking the Digital Divide. MIT Press.

West, J. C. (2011). Without a net: librarians bridging the digital divide. Libraries Unlimited.

Wifi Forward. (2020). TV white spaces may be key to connecting millions of Americans: Here's how.

http://wififorward.org/news/tv-white-spaces-may-be-key-to-connecting-millions-of-ameri cans-heres-how/

Yu, L. (2006). Understanding information inequality: Making sense of the literature of the information and digital divides. Journal of Librarianship and Information Science, 38(4), 229-252. https://doi.org/10.1177/0961000606070600 